\title{
Identification, characterization and microRNA expression profiling of side population cells in human oral squamous cell carcinoma Tca8113 cell lines
}

\author{
WEI LUO $^{1 *}$, RONG-SEN LIU ${ }^{1 *}$, LING-LING E $^{1}$, YANG BAI $^{1}$, XIANG-PAN KONG ${ }^{2}$, \\ HUA-WEI LIU ${ }^{1}$, HAO WU ${ }^{1}$ and HONG-CHEN LIU ${ }^{1}$ \\ ${ }^{1}$ Institute and Department of Stomatology, Chinese People's Liberation Army General Hospital, Beijing 100853; \\ ${ }^{2}$ Department of Oral and Maxillofacial-Head and Neck Oncology, Beijing Stomatological Hospital, \\ Capital Medical University, Beijing 100050, P.R. China
}

Received February 10, 2018; Accepted October 22, 2018

DOI: $10.3892 / \mathrm{mmr} .2020 .11073$

\begin{abstract}
The present study aimed to evaluate the stem cell markers, characteristics and biological functions of cancer stem-like side population (SP) cells in human oral cancer. SP cells were isolated from the human oral squamous cell carcinoma Tca 8113 cell line by Hoechst 33342 fluorescence dye and flow cytometry. The colony forming and proliferative capability of SP and non-SP cells were detected using a live-cell analysis system in vitro. The number of cells expressing stem cell markers was compared between SP cells and non-SP cells by flow cytometry. Reverse transcription-quantitative polymerase chain reaction and western blotting were used to detect the mRNA and protein expression levels of stem cell genes, respectively. Differential expression of microRNAs (miRNAs) in SP and non-SP cells was determined by microarray hybridization and an miRNA regulation network was produced. With regard to the proliferation capability, SP cells reached $60.0 \%$ confluence after $40 \mathrm{~h}$ of growth compared with $35.1 \%$ confluence for non-SP cells $(\mathrm{P}<0.05)$. The number of colonies in SP cells was 43.1 \pm 9.2 compared with $33.0 \pm 8.2$ of non-SP cells $(\mathrm{P}<0.05)$. The aldehyde dehydrogenase-1 (ALDH1)-positive cell number in the SP cells was increased by 10 times compared with the non-SP cells $(\mathrm{P}<0.01)$. The mRNA and protein expression levels of ALDH1, SRY-box 2, POU class 5 homeobox 1 and Nanog homeobox in SP cells were significantly higher compared with non-SP cells $(\mathrm{P}<0.05)$. Microarray hybridization demonstrated that 21 miRNAs were
\end{abstract}

Correspondence to: Dr Hong-Chen Liu, Institute and Department of Stomatology, Chinese People's Liberation Army General Hospital, 28 Fuxing Road, Beijing 100853, P.R. China

E-mail: liu-hc301@hotmail.com

*Contributed equally

Key words: cancer stem cells, side population cells, Tca8113, microRNA network upregulated and 13 miRNAs were downregulated in SP cells compared with non-SP cells. SP cells in Tca8113 demonstrated greater capability of proliferation and colony formation compared with non-SP cells in vitro. Stem cell markers were overexpressed in SP cells compared with non-SP cells.

\section{Introduction}

Head and neck cancers are the sixth most common cancer type affecting 650,000 people and causing 350,000 mortalities per year, worldwide (1). Oral cancer is the most common type of head and neck cancer (2). Annually, $7 \%$ of cancer-associated mortality in males and $4 \%$ in females is attributed to oral cancer (2). Oral squamous cell carcinoma (OSCC) is one of the most common malignant oral cancers. In recent years, the rapid development of the cancer stem cell (CSC) theory provided a novel understanding of tumorigenesis (3). The CSC population possesses characteristics associated with stem cells, including self-renewal and exhibits high in vivo tumorigenicity and differentiation potential, in addition to multidrug and apoptotic resistance (4-6). CSCs additionally have the capacity to promote tumor metastasis and progression, and have been identified in multiple types of cancer $(7,8)$. Side population (SP) cells exhibit low fluorescence characteristics following staining of CSCs with Hoechst 33342 and flow cytometry analysis, and thus may be sorted (8). Kondo et al (9) isolated SP cells from C6 glioma cells (0.4\%), B104 neuroblastoma cells (0.4\%), HeLa carcinoma cells (1.2\%) and MCF7 breast cancer cells (2.0\%), suggesting a small population of SP cells in multiple cancer cell lines. Additionally, the sorted C6 SP cells were found to generate SP and non-SP cells under certain conditions and share a number of characteristics with CSCs; in particular, they possess the capacity for tumor initiation and express stem-like genes. The SP cells in OSCC have been investigated previously in certain studies. The percentage of SP cells vary in different OSCC cell lines, ranging between 0.2 and $9.8 \%$ of the total cell population in the cell lines (10-14). The SP cells isolated from Tca/cisplatin, SCC-25, SCC-55, SAS or OECM1 cell lines have tumor stem cell phenotypes, including high tumorigenicity, differentiation 
ability and/or chemoresistance (10-13). However, to the best of our knowledge, the role of SP cells in the Tca8113 cell line has not been assessed.

Aldehyde dehydrogenase-1 (ALDH1), CD44 antigen (CD44) and CD133 antigen (CD133) are the most common markers of CSCs. CD44 is highly expressed in numerous types of CSCs $(10,15)$. The transcription factor Nanog is activated when CD44 binds to hyaluronic acid, promoting cell self-renewal and pluripotency (16). Additionally, Nanog activates the downstream multidrug resistance gene 1 (15). The expression of CD133 in OSCC is significantly higher than in normal tissue and benign tumor (11). Furthermore, Zhang et al (17) identified a small subpopulation (1-2\%) of $\mathrm{CD}_{133}{ }^{+} \mathrm{CSC}$ that may confer chemo-resistance in OSCC. ALDH1 is a cytoplasmic enzyme that is able to oxidize acetaldehyde to carboxylic acids (18). Elevated ALDH1 expression in OSCC tissue is associated with local recurrence (19). ALDH1 is also a potential marker of CSCs in numerous solid tumors that are associated with poor clinical outcome (20-23). However, it is not clear whether ALDH1 is one of the CSCs markers of oral cancer. It has been reported that ALDH combines with CD133 to confer a high tumorigenicity in liver or ovarian CSCs $(22,24)$. In addition, patients with oral leukoplakia harboring co-expression of ALDH1 and CD133 exhibited a high risk of malignant transformation to oral cancer (25). As documented, different CSCs markers are expressed in the SP cells derived from different OSCC cell lines (10-13). Therefore, it is necessary to detect the specific markers in Tca8113 SP cells.

In addition, microRNA (miRNA/miR) are non-coding single-strand RNA molecules of 19-25 nucleotides, which are involved in a series of important processes, including cell proliferation, differentiation and apoptosis. An increasing number of studies have demonstrated that miRNA is involved in various tumors development process, including OSCC. miR-375, miR-127, miR-137 (hypermethylation), the miR-200 family and miR-205 are promising candidates associated with OSCC (26). Overexpression of miR-155, let-7i and miR-146a are associated with tumor progression and metastases (27). However, the involvement of miRNAs in SP cells is unclear.

In the present study, the proliferation ability, expression of stem genes and CSCs markers were compared between SP cells and non-SP cells. Differential miRNA expression profiles in Tca8113 tumor stem cells were detected by microarray analysis. These experiments provided a more comprehensive understanding of the biological characteristics of SP cells.

\section{Materials and methods}

Cell lines and cell culture. The human OSCC Tca8113 cell line [provided by the cell bank of the Chinese Academy of Sciences (Beijing, China)] was cultured in Dulbecco's modified Eagle's medium (DMEM)/F12 (Gibco; Thermo Fisher Scientific, Inc.) containing $10 \%$ fetal bovine serum [termed serum-supplemented medium (SSM); Gibco; Thermo Fisher Scientific, Inc.] in $5 \% \mathrm{CO}_{2}$ and saturated humidity at $37^{\circ} \mathrm{C}(28)$. The cells were digested with $0.25 \%$ trypsin (Hyclone; GE Healthcare Life Sciences) containing $0.02 \%$ EDTA for $5 \mathrm{~min}$ followed by centrifugation (Eppendorf) at $400 \mathrm{x}$ g for $5 \mathrm{~min}$ at $4^{\circ} \mathrm{C}$. Subsequently, the cells were cryopreserved and stored in a freezer (Sanyo Electric Co., Ltd.) at $-80^{\circ} \mathrm{C}$ containing $10 \%$ dimethyl sulfoxide (MP Biomedicals, LLC), 20\% fetal bovine serum and 70\% DMEM/F12 culture medium (29). Prior to use, cells were resuspended in a $37^{\circ} \mathrm{C}$ water bath for $1 \mathrm{~min}$ and cultured in $4 \mathrm{ml} \mathrm{SSM}$ overnight.

Isolation of SP cells by Hoechst 33342 fluorescence activated cell sorting. Tca8113 cells were washed with PBS, digested by trypsin, and $1 \times 10^{6} / \mathrm{ml}$ cells were collected. Subsequently, $5 \mu \mathrm{g} / \mathrm{ml}$ Hoechst 33342 (Sigma-Aldrich; Merck KGaA) was added at $37^{\circ} \mathrm{C}$ for $90 \mathrm{~min}$. In total, $25 \mu \mathrm{g} / \mathrm{ml}$ ATP-binding cassette $(A B C)$ sub-family $G$ member 2 inhibitor verapamil (30) was added in advance as the negative control. Upon staining, the cells were centrifuged for $10 \mathrm{~min}$ at $4^{\circ} \mathrm{C}$ at $150 \mathrm{xg}$ to discard the supernatant, added to $500 \mu \mathrm{l}$ PBS with $10 \mu \mathrm{g} / \mathrm{ml}$ propidium iodide and sorted by flow cytometry. The dye was excited at 351-364 $\mathrm{nm}$ and the fluorescence measured with a $515 \mathrm{~nm}$ SP filter and a 608 long pass edge optical filter. The SP and non-SP cells were collected and counted under a light microscope (x200).

Sphere culture. Following sorting, SP and non-SP cells were placed in ultra-low attachment plates under stem cell conditions by culturing in serum-free medium (SFM) containing $10 \mathrm{ng} / \mathrm{ml}$ epidermal growth factor (EGF), $10 \mathrm{ng} / \mathrm{ml}$ basic fibroblast growth factor (bFGF) and $1 \times$ B27 with $5 \% \mathrm{CO}_{2}$ and saturated humidity at $37^{\circ} \mathrm{C}$.

Cell proliferation and scratch-wound assays in vitro. The SP and non-SP cells were digested by $0.25 \%$ trypsin, and filtered using 40- $\mu \mathrm{m}$ nylon mesh. Subsequently, cells were seeded in 96 -well plates $\left(5 \times 10^{3}\right.$ cells/well in the cell proliferation assay; $2.5 \times 10^{4}$ cells/well in the wound scratch assay), and $200 \mu \mathrm{l}$ DMEM/F12 was added in complete medium in an incubator with $5 \% \mathrm{CO}_{2}$ at $37^{\circ} \mathrm{C}$. A 96-well wound maker was used to test the wound-healing rate (31). Data from the cell proliferation and scratch-wound assays were collected every $2 \mathrm{~h}$ for $42 \mathrm{~h}$ and analyzed using the IncuCyte Zoom Live-Cell Analysis System (Essen Bioscience).

Colony formation assay. The SP and non-SP cells were digested in $0.25 \%$ trypsin and filtered using $40-\mu \mathrm{m}$ nylon mesh. Subsequently, cells were seeded in 6-well plates at a density of 200 cells/well and incubated at $5 \% \mathrm{CO}_{2}$ and $37^{\circ} \mathrm{C}$ for 14 days. Following the formation of colonies visible to the naked eye, the cell colonies were washed with PBS and subsequently fixed with $4 \%$ methanol at room temperature for $15 \mathrm{~min}$, followed by incubation with $0.5 \%$ crystal violet at room temperature for $30 \mathrm{~min}$ and rinsed with deionized distilled water. The number of colonies was counted.

Flow cytometry to detect stem marker-positive cells. Sphere-forming SP cells and non-SP cells at $1 \times 10^{6} / \mathrm{ml}$ were collected and washed with PBS. After centrifugation at $400 \mathrm{x} \mathrm{g}$ for $15 \mathrm{~min}$ at $4^{\circ} \mathrm{C}$, cells were fixed in pre-cooled ethanol at $4^{\circ} \mathrm{C}$ overnight. On the next day, cells were washed with PBS, and incubated with FITC-conjugated anti-ALDH1 antibodies (1:100, Beijing Biosynthesis Biotechnology Co., Ltd.; cat. no. bs-10162R-FITC); PE-conjugated anti-CD133 antibodies (1:100, Miltenyi Biotech, Inc.; cat. no. 130-111-079); 
APC-conjugated anti-CD44 antibodies (1:100, eBioscience; Thermo Fisher Scientific, Inc.; cat. no. 17-0441-81) at $37^{\circ} \mathrm{C}$ for $1 \mathrm{~h}$ in the dark. Subsequently, flow cytometric analysis was performed to detect the CD44, CD133 and ALDH1 positive cells in the sphere-forming SP cells and non-SP cells using a flow cytometry (FACSCalibur; BD Biosciences). Additionally, the sphere-forming SP cells at $3 \times 10^{5} / \mathrm{ml}$ were seeded in SSM for 14 days to induce differentiation. Furthermore, the proportions of CD44, CD133 and ALDH1 positive cells were determined following differentiation.

Reverse transcription-quantitative polymerase chain reaction $(R T-q P C R)$. Total RNA from SP cells and non-SP cells was extracted using TRIzol ${ }^{\circledR}$ reagent (Invitrogen; Thermo Fisher Scientific, Inc.). An ultraviolet (UV) spectrophotometer was used to detect the concentration of RNA by measuring the optical density (OD)260. The OD260/OD280 ratios of 1.8-2.0 were required. In total, $1 \mu 1500 \mathrm{ng} / \mu \mathrm{l}$ RNA was used for cDNA synthesis, according to the manufacturer's protocol. RT was performed for one cycle under the following conditions; $37^{\circ} \mathrm{C}$ for $15 \mathrm{~min}$ and $85^{\circ} \mathrm{C}$ for $5 \mathrm{sec}$ using the RT System (Promega Corporation). The RT reactions contained $1 \mu \mathrm{l}$ RNA, $2 \mu 15 \mathrm{X}$ PrimeScript Buffer, 0.5 $\mu$ 1 PrimeScript RT Enzyme Mix, $0.5 \mu 1$ Oligo dT Primer, $0.5 \mu 1$ Random 6-mers and 5.5 $\mu 1$ RNase Free $\mathrm{dH}_{2} \mathrm{O}$.

qPCR was performed using a StepOne Real-Time PCR System (Applied Biosystems; Thermo Fisher Scientific, Inc.) with One Step SYBR PrimeScript RT-qPCR kit II (Takara Bio, Inc.). The primer sequences for POU class 5 homeobox 1 (Oct4), nanog homeobox (Nanog), SRY-box 2 (Sox2), ALDH1 and CD133 are presented in Table I. qPCR was performed under the following conditions: $95^{\circ} \mathrm{C}$ for $10 \mathrm{sec}$; 40 cycles of $95^{\circ} \mathrm{C}$ for $5 \mathrm{sec}$; and $60^{\circ} \mathrm{C}$ for $30 \mathrm{sec}$. The qPCR reactions contained $2 \mu \mathrm{l}$ cDNA, $10 \mu \mathrm{l}$ FastStart SYBR Green Master, $0.8 \mu \mathrm{l}$ forward primer, $0.8 \mu \mathrm{l}$ PCR forward primer and $6.4 \mu \mathrm{l}$ RNase Free $\mathrm{dH}_{2} \mathrm{O}$. To quantify alterations in gene expression, the $2^{-\Delta \Delta \mathrm{Cq}}$ method (32) was used to calculate the relative gene expression following normalization using the expression of GAPDH.

The SP cells were placed under SSM condition for 14 days to induce differentiation. The gene expressions were examined in non-SP cells and in SP cells prior to and following differentiation.

Western blot analysis. Cells were first lysed with radioimmunoprecipitation buffer (Cell Signaling Technology) and $5 \mu \mathrm{g}$ of proteins were separated using 10\% SDS-PAGE gels and transferred to a polyvinylidene difluoride membranes subsequent to cell protein concentration quantification with a Bio-Rad assay kit (cat. no. 5000002; Bio-Rad Laboratories, Inc.). The membranes were blocked in 5\% non-fat milk at room temperature for $1 \mathrm{~h}$ and incubated with primary antibodies; rabbit polyclonal anti-ALDH1 (1:200; Santa Cruz Biotechnology, Inc., cat. cat. no. sc-50385), rabbit polyclonal anti-Oct4 (1:200; Cell Signaling Technologies Biological Reagents, Co., Ltd., cat. no. 2750), rabbit polyclonal anti-Nanog (1:200; Santa Cruz Biotechnology, Inc., cat. no. sc-33759) rabbit polyclonal anti-Sox2 (1:200; Santa Cruz Biotechnology, Inc., cat. no. sc-20088), and GAPDH (internal control; 1:200 Santa Cruz Biotechnology, Inc., cat. no. sc-20358) at $4^{\circ} \mathrm{C}$ overnight (33). Following washing three times in TBS/0.1\% Tween-20, the membranes underwent hybridization with a horseradish peroxidase-conjugated ant-rabbit secondary antibody (1:1,000; Thermo Fisher Scientific, Inc., cat. no. A24531) for $1 \mathrm{~h}$ at room temperature. Signals were subsequently visualized with the Beyo Enhanced Chemiluminescent Plus detection kit (Beyotime Institute of Biotechnology). The relative level of protein expression was measured based on densitometry using Gel-Pro Analyzer version 3.0 (Media Cybernetics, Inc.).

The SP cells were cultured under SSM condition for 14 days to induce differentiation. The protein expressions were tested in non-SP cells and in SP cells prior to and following differentiation.

miRNA expression profiles in Tca8113 SP cells. Total RNA was isolated using TRIzol ${ }^{\circledR}$ (Invitrogen; Thermo Fisher Scientific, Inc.) and miRNeasy mini kit (Qiagen $\mathrm{GmbH}$ ) according to the manufacturer's protocol, which efficiently recovered all RNA species, including miRNAs. RNA quality and quantity were measured using nanodrop spectrophotometer (ND-1000; NanoDrop Technologies; Thermo Fisher Scientific, Inc.) and RNA Integrity was determined by gel electrophoresis. The miRCURY ${ }^{\mathrm{TM}} \mathrm{Hy}^{\mathrm{TM}} / \mathrm{Hy}^{\mathrm{TM}}$ Power labeling kit (Exiqon A/S) was used, according to the manufacturer's protocol, for miRNA labelling. The $\mathrm{Hy}^{\mathrm{TM}}$-labeled samples were hybridized on the miRCURY ${ }^{\mathrm{TM}}$ LNA $^{\mathrm{TM}}$ Array (v18.0; Exiqon A/S) according to the manufacturer's protocol. In total, $25 \mu \mathrm{l}$ mixture from Hy $3^{\mathrm{TM}}$-labeled samples with $25 \mu 1$ hybridization buffer were denatured for $2 \mathrm{~min}$ at $95^{\circ} \mathrm{C}$, incubated on ice for $2 \mathrm{~min}$ and subsequently hybridized to the microarray for $16-20 \mathrm{~h}$ at $56^{\circ} \mathrm{C}$ in a 12-Bay Hybridization Systems (NimbleGen Systems, Inc.). Scanned images were imported into Axon GenePix Pro 6.0 software (Molecular Devices, LLC) for grid alignment and data extraction. Replicated miRNAs were averaged and miRNAs of which intensities $\geq 30$ in all samples were selected for calculating the normalization factor. Expressed data were normalized using the Median normalization (34). Following normalization, significant differentially expressed miRNAs between SP and non-SP cells were identified by Volcano Plot filtering. Hierarchical clustering was performed using MultiExperiment Viewer software (v4.6; The Institute for Genomic Research, Rockville, MA, USA) (35). The genes targeted by the differentially expressed miRNAs were predicted, and the protein-protein interactions (PPIs) between these proteins/genes were further predicted based on text-mining and public databases including Gene Ontology, KEGG, Pfam and InterPro. The predicted miRNA-gene relationships and PPIs were utilized to establish a miRNA-gene-gene regulatory network. The PPIs in the network was statistically analyzed by computing centered Pearson correlation coefficient (36), and the PPI number of each gene (that is, the number of genes interacting with a certain gene) in this network was counted.

Statistical analysis. Data were derived from at least three independent repeats for each experiment. Statistical analysis was performed using a Student's t-test or $\chi^{2}$ test to compare differences in values between the SP and non-SP cells using SPSS 20.0 (IBM, Corp., Armonk, NY, USA). The results are presented as the mean \pm standard deviation. $\mathrm{P}<0.05$ was considered to indicate a statistically significant difference. 
Table I. Primers for the polymerase chain reaction assays.

\begin{tabular}{ll}
\hline Gene & \multicolumn{1}{c}{ Primer (5'-3') } \\
\hline OCT4 & Forward: CTTGAATCCCGAATGGAAAGGG \\
& Reverse: CCTTCCCAAATAGAACCCCCA \\
NANOG & Forward: AAGGTCCCGGTCAAGAAACAG \\
& Reverse: CTTCTGCGTCACACCATTGC \\
SOX2 & Forward: TACAGCATGTCCTACTCGCAG \\
& Reverse: GAGGAAGAGGTAACCACAGGG \\
ALDH1A1 & Forward: CTGCTGGCGACAATGGAGT \\
& Reverse: CGCAATGTTTTGATGCAGCCT \\
CD133 & Forward: GGCCCAGTACAACACTACCAA \\
& Reverse: ATTCCGCCTCCTAGCACTGAA \\
GAPDH & Forward: GGTGAAGGTCGGAGTCAACG \\
& Reverse: CAAAGTTGTCATGGATGHACC
\end{tabular}

OCT4, POU class 5 homeobox 1; NANOG, nanog homeobox; SOX2, SRY-box 2; ALDH1A1, aldehyde dehydrogenase 1 family member A1; CD133, CD133 antigen.

\section{Results}

SP cells in Tca8113 cell line. SP cells were sorted by flow cytometry following Hoechst 33342 fluorescence staining. As demonstrated in Fig. 1A, SP cells in Tca8113 cells accounted for $0.70 \pm 0.22 \%$, significantly increased compared with $0.10 \pm 0.03 \%$ following treatment with verapamil, a selective $\mathrm{ABC}$ transporter inhibitor $(\mathrm{P}<0.05)$. Verapamil, a calcium channel blocker and non-specific inhibitor of ABC transporters, has been shown to inhibit SP generation (37).

Sorted SP and non-SP cells were cultured under stem cell conditions (SFM containing EGF, bFGF and B27). After 10 days, the SP cells formed obvious spheres (Fig. 1B); however, non-SP cells were barely able to survive. Therefore, for the biological morphology observation, SP spheres were collected, resuspended and cultured in SSM for differentiation; whereas, sorted non-SP cells were directly cultured in SSM. Following culture for one day, the SP cells demonstrated slender protrusions and loose connections between cells compared with the non-SP cells (Fig. 1C).

Proliferation, migration and colony formation ability of SP cells. The results of IncuCyte Zoom demonstrated that the proliferative capability of SP cells was increased compared with the non-SP cells $(60.0 \%$ confluence compared with $35.1 \%$ confluence after $40 \mathrm{~h}$ growth; $\mathrm{P}<0.05$; Fig. $2 \mathrm{~A})$. The scratch-wound assay demonstrated that SP cells migrated to the center after $42 \mathrm{~h}$, and the wound density was $55.2 \%$, significantly increased compared with non-SP cells $(47.5 \%$; $\mathrm{P}<0.05$; Fig. 2B and C). To further evaluate the proliferative capacity of SP cells and non-SP cells, the colony formation assay was applied to detect the reproductive capacity of the cells. The number of colonies formed from SP cells was significantly increased compared with non-SP cells, which was 43.1 49.2 and 33.0 \pm 8.2 , respectively $(\mathrm{P}<0.05$; Fig. $2 \mathrm{D}$ and $\mathrm{E})$.

Expression of stem cell markers $\mathrm{CD}_{4} 4^{+}, \mathrm{CD} 133^{+}$and $A L D H 1^{+}$. As presented in Fig. 3A, cultured SP or non-SP cells were incubated with anti-ALDH1, anti-CD133 and anti-CD44 antibodies together, and subjected to flow cytometry analysis. The results revealed that there were no significant differences, regarding the percentage of $\mathrm{CD} 44^{+}$and $\mathrm{CD} 133^{+}$cells between SP and non-SP cells. Fig. 3B demonstrated the percentage of only $\mathrm{ALDH}^{+}$cells of cultured SP or non-SP cells following incubation of anti-ALDH1, anti-CD133 and anti-CD44 antibodies together. The percentage of $\mathrm{ALDH} 1^{+}$cells was markedly higher in SP cells compared with in non-SP cells at day $0(7.1 \%$ vs. $0.5 \%)$. When SP cells were placed into the SSM differentiation condition for 14 days, the percentage of $\mathrm{ALDH}^{+}$cells decreased to $0.5 \%$, which was similar to the non-SP cells $(0.6 \%)$. Similar results were obtained following three independent experiments. There were a significantly higher percentage of $\mathrm{ALDH}^{+}$cells in SP cells compared with non-SP cells prior to differentiation $(\mathrm{P}<0.01$; Fig. $3 \mathrm{C})$.

Evaluation of expression of stem genes and CSCs surface markers by RT-qPCR and western blotting. The mRNA expression of Sox2, Oct4, Nanog, CD133 and ALDH1 were detected by RT-qPCR. The results demonstrated higher mRNA expression levels of ALDH1, Sox2, Oct4 and Nanog in the SP cells ( $\mathrm{P}<0.05$; Fig. 4A), and the expression of CD133 exhibited no significant difference from the non-SP cells ( $\mathrm{P}>0.05$; Fig. 4A). This was further confirmed by western blotting. Compared with the non-SP cells, the protein expression levels of ALDH1, Nanog, Oct4 and Sox 2 were higher in the SP cells (Fig. 4B). When the SP cells were placed into the SSM differentiation condition for 14 days, SP cells seeded in SSM and non-SP cells had the same mRNA $(\mathrm{P}>0.05)$ and protein expression levels (Fig. 4C and D).

Differential expression of miRNAs in SP and non-SP cells. Prior to miRNA expression profiling, the quantitative detection was conducted using a UV spectrophotometer. The OD260/280 values of the SP and non-SP cell samples (each type of sample had three repeats) were about 2.0, and the values 
Table II. Prior to microRNA expression profiling, the RNA quantification and quality assurance were determined.

\begin{tabular}{lcccccc}
\hline Samples & $\begin{array}{c}\text { OD260/280 } \\
\text { ratio }\end{array}$ & $\begin{array}{c}\text { OD260/230 } \\
\text { ratio }\end{array}$ & $\begin{array}{c}\text { Concentration } \\
(\mathrm{ng} / \mu \mathrm{l})\end{array}$ & $\begin{array}{c}\text { Volume } \\
(\mu \mathrm{l})\end{array}$ & $\begin{array}{c}\text { Quantity } \\
(\mathrm{ng})\end{array}$ & $\begin{array}{c}\text { QC result } \\
\text { (pass or fail) }\end{array}$ \\
\hline SP cells & 1.95 & 2.05 & 641.82 & 40 & $25,672.80$ & Pass \\
& 1.90 & 2.15 & 387.47 & 40 & $15,498.80$ & Pass \\
Non-SP cells & 1.94 & 2.28 & 398.44 & 40 & $15,937.60$ & Pass \\
& 2.04 & 2.24 & 818.34 & 40 & $32,733.60$ & Pass \\
& 2.06 & 2.22 & 990.04 & 40 & $39,601.60$ & Pass \\
& 2.08 & 1.97 & 888.39 & 50 & $44,419.50$ & Pass \\
\hline
\end{tabular}

SP, side population; OD, optical density; QC, quality control.
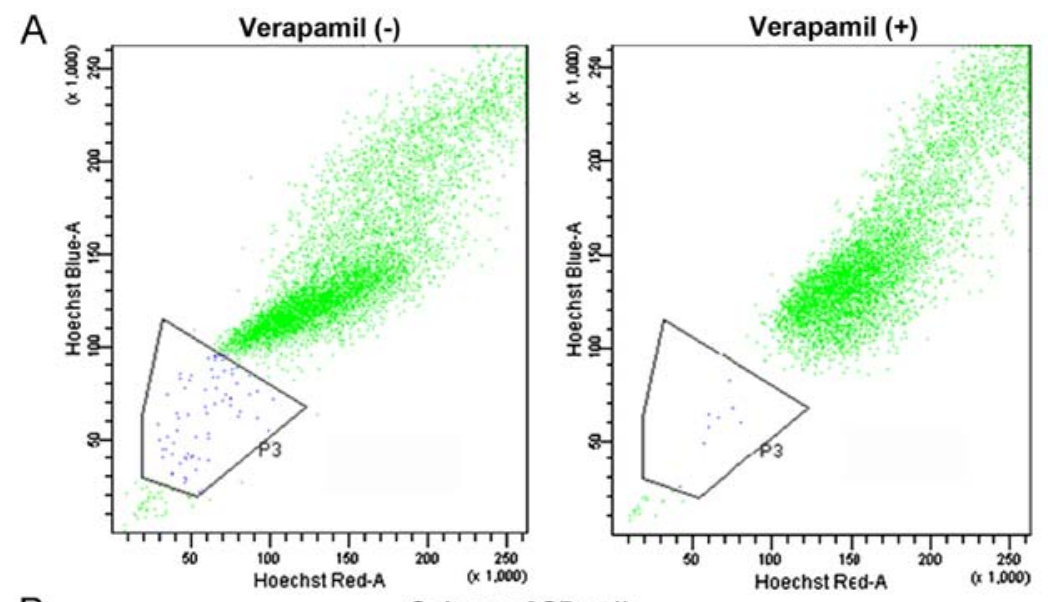

B

Sphere of SP cells
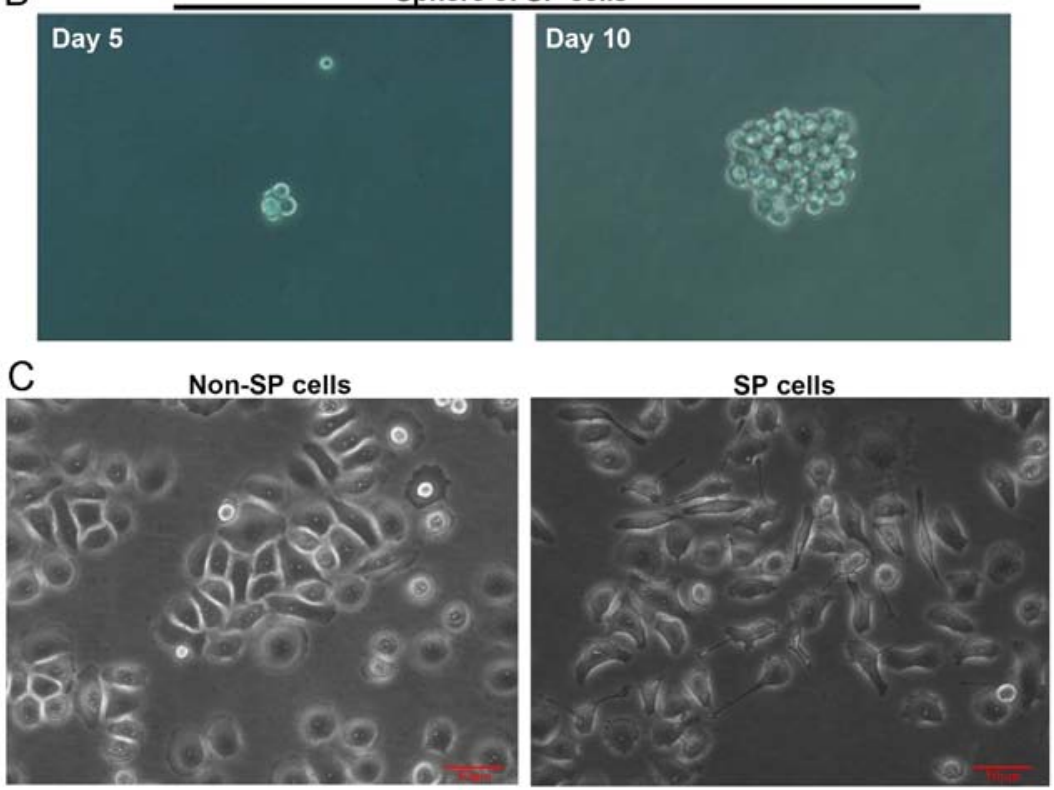

Figure 1. SP cells from the Tca8113 cell line are sorted. (A) SP cells in Tca8113 cell line were sorted by flow cytometry following Hoechst 33342 staining. The selective ATP-binding cassette transporter inhibitor (50 $\mu \mathrm{m}$ verapamil) was used as negative control. (B) Representative images of sphere of sorted SP cells on day 5 and day 10 following culture under stem cell conditions (serum-free medium containing epidermal growth factor, basic fibroblast growth factor and B27). Magnification, x40. (C) Morphology characteristic of non-SP cells and SP cells. Scale bar, $50 \mu \mathrm{m}$. SP, side population.

of OD260/230 were $>1.8$ (Table II). GenePix Pro 6.0 was used to identify 34 miRNAs that were significantly differentially expressed, of which, 21 miRNAs were upregulated and 13 miRNAs were downregulated, based on a fold change $>2.0$ and $\mathrm{P}<0.05$ threshold in SP cells compared with the non-SP cells (Fig. 5). The miRNA-gene-gene regulatory network was constructed, involving 5 miRNAs (has-miR-140-5p, has-miR-3686, has-miR-92b-5p, has-miR-582-5p and 

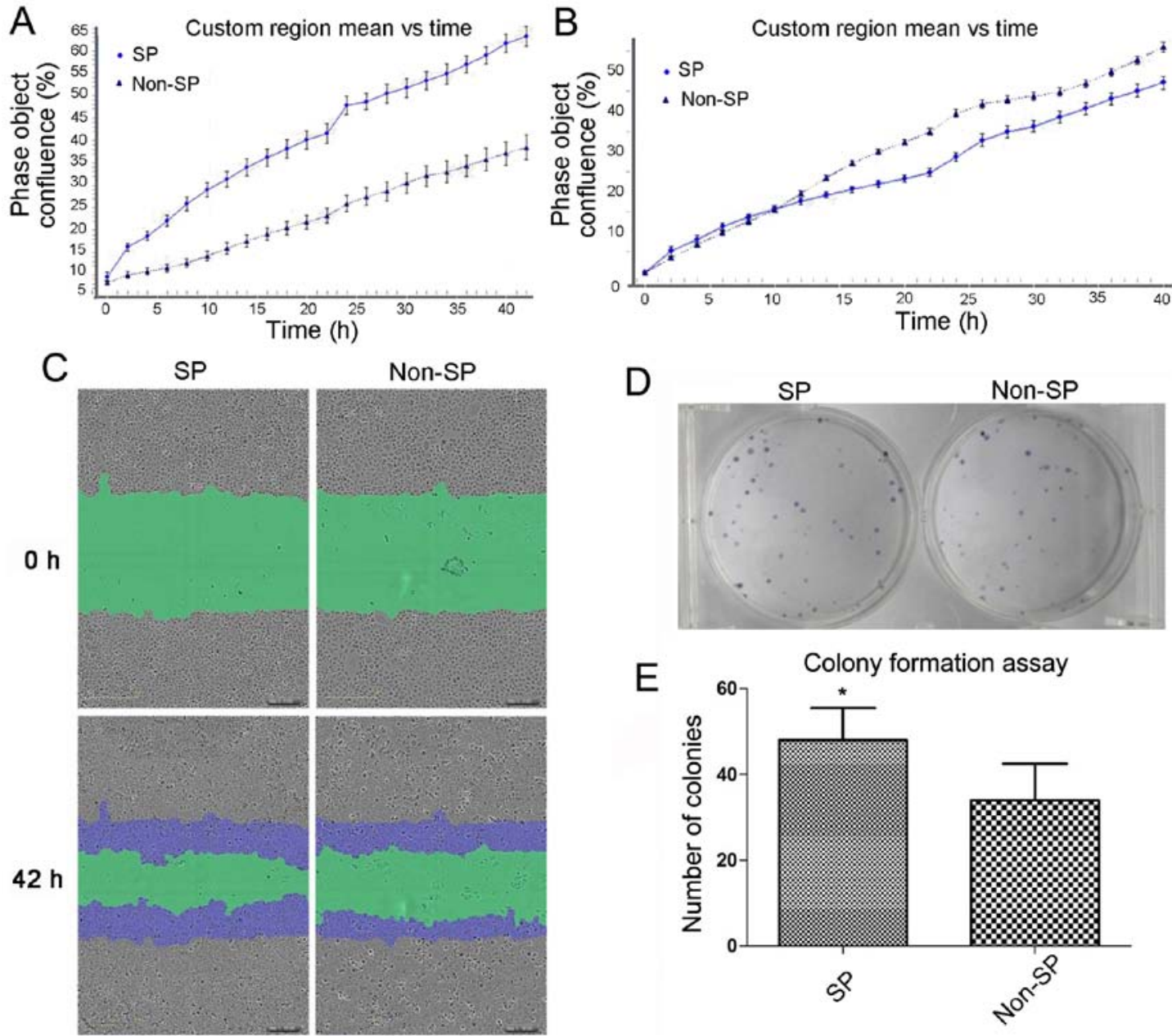

Figure 2. Verification of cell proliferation, migration and colony formation efficiency of sorted SP and non-SP cells. (A) Cell confluence of SP cells and non-SP cells. (B) Relative wound density of SP cells and non-SP cells. (C) Scratch test results of SP cells and non-SP cells. The green region represents the area without cells; the blue region represents the area with migrated cells. Magnification, x10. (D) Colony forming assay of SP cells and non-SP cells. (E) Colony formation efficiency of SP and non-SP cells. "P<0.05 vs. non-SP cells. SP, side population.

has-miR-627-5p) and 176 genes (Fig. 6A). The number of genes in this network was obtained (Fig. 6B). The PPI number of each gene in this network was counted, and the top five genes with high PPI numbers were epidermal growth factor receptor (EGFR), integrin subunit $\alpha 2$ (ITGA2), protein kinase cAMP-activated catalytic subunit $\beta$ (PRKACB), cyclin dependent kinase (CDK1) and cyclin D1 (CCND1), which require further investigation.

\section{Discussion}

During the last decades, the existence of CSCs has been identified in hematopoietic cancers in addition to a variety range of solid tumors, including breast, brain, lung, colon, prostate, head and neck, and other cancer types $(38,39)$. Mackenzie (40) identified that only a small number of cells in the OSCC had the ability to clone. Locke et al (41) observed that even the long-term culture of human OSCC additionally contains different types of cell subsets in vitro with normal oral epithelial stem cells and transient amplifying cells, which correspond to a small group of cells with stem cell-like characteristics. Although the study of CSC in hematological malignancies and specific solid tumors has progressed, the methods of isolation and identification of CSCs still require optimization as a number of CSCs surface markers have not been identified.

The percentage of SP cells vary in different OSCC cell lines, ranging between 0.2 and $9.8 \%$ of the total cell populations in the cell lines (10-14). With regards to the Tca8113 cell line, Zhang et al (10) reported a percentage of $0.2 \%$. In the present study, the Hoechst 33342 staining demonstrated that $<1 \%$ Tca8113 SP cells were sorted, confirming only a small fraction of the number of SP cells is present in the Tca8113 cell line.

Cell proliferation and migration ability were recorded using IncuCyte Zoom, thus enabling the determination of cell growth with high accuracy during live cell imaging, and eliminating the requirement for destroying cellular structures for other methods. The results of the imaging demonstrated that compared with the non-SP cells, SP cells derived from the Tca8113 OSCC cell line exhibited increased proliferation, colony-forming and migration ability. In the present study, the expression of CSC markers, including CD133, CD44 and ALDH1, were investigated in the sorted SP cells. A small subpopulation of $\mathrm{CD} 133^{+} \mathrm{CSC}$ in OSCC cell lines (including SCC-016, SCC-076 and SCC-29B) had been isolated in a previous study, and $\mathrm{CD} 133^{+} \mathrm{CSC}$ demonstrated 

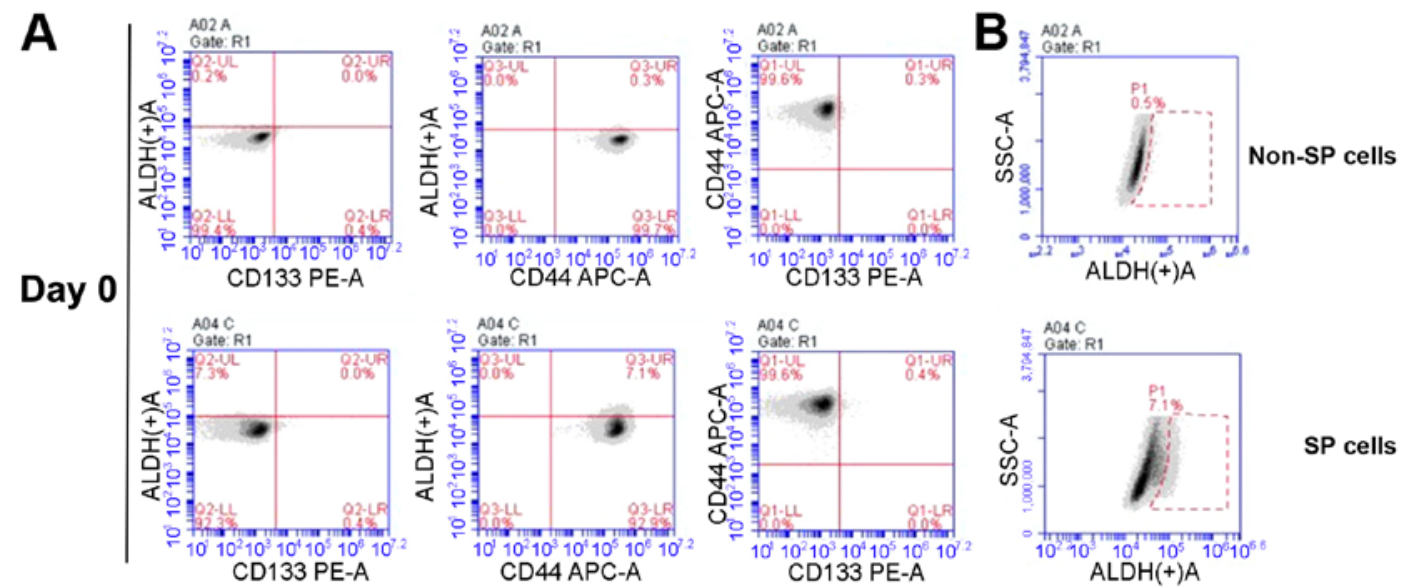

SP cells
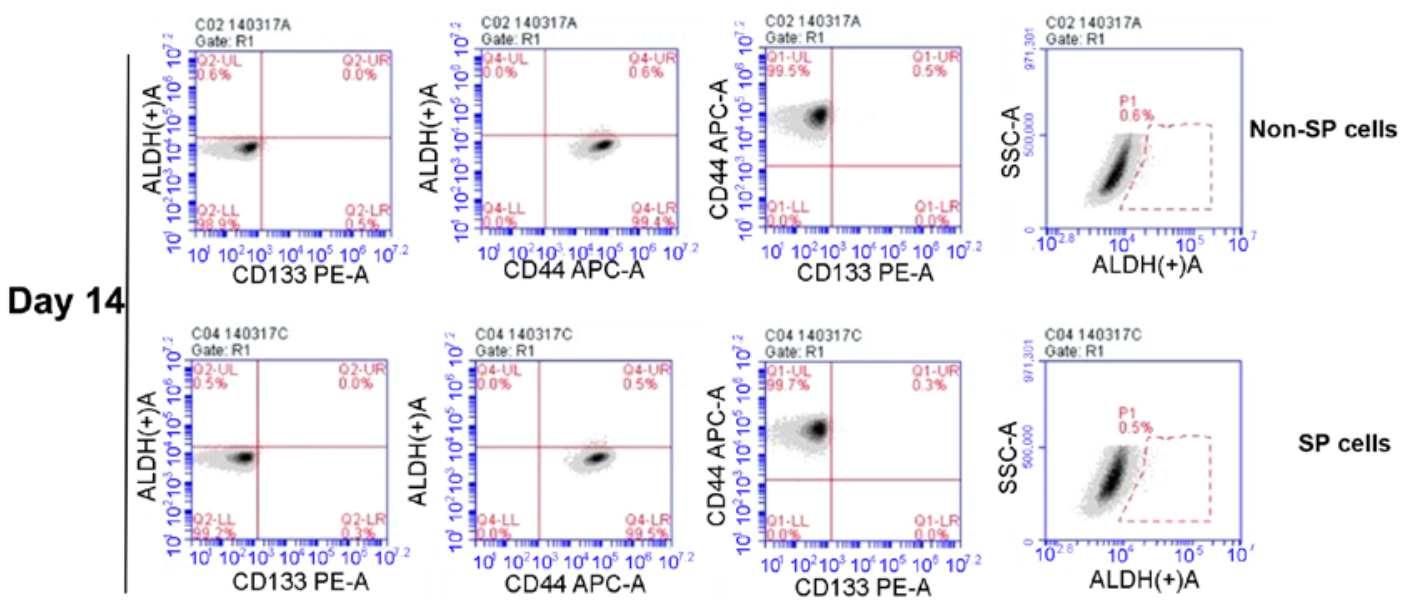

SP cells


Figure 3. Expression of ALDH1, CD133 and CD44 prior to and following induction of differentiation in SP cells. SP or non-SP cells were incubated with anti-ALDH1, anti-CD133 and anti-CD44 antibodies together, and subjected to flow cytometry analysis. (A) Percentage of ALDH1 ${ }^{+}$, CD133 ${ }^{+}$or CD44 ${ }^{+}$cells in non-SP and SP cells prior to (day 0) and following differentiation (day 14). During flow cytometry analysis, Left, cells were analyzed for the expression of ALDH1 and CD133; Middle, cells were analyzed for the expression of ALDH1 and CD44; Right, cells were analyzed for the expression of CD133 and CD44. All these were conducted in the same population of SP or non-SP cells. (B) Percentage of only ALDH $1^{+}$cells in the same population of non-SP and SP cells in A prior to (day 0) and following differentiation (day 14). (C) Percentage of $\mathrm{ALDH}^{+}$cells in non-SP and SP cells prior to (day 0) and following differentiation (day 14) after three independent experiments. ${ }^{* *} \mathrm{P}<0.01$. ALDH1, aldehyde dehydrogenase-1; CD44, CD44 antigen; CD133, CD133 antigen; PE, phycoerythrin; APC, allophycocyanin; SSC, side scatter; SP, side population.

high clonogenicity, invasiveness and tumorigenicity (17). The stem-like SP cells derived from the Tca/cisplatin OSCC cell line exhibited a higher expression level of CD44 compared with the non-SP cells (10). Chiou et al (13) additionally identified SP cells in the SCC-55 OSCC cell line that overexpressed CD44 (11). However, the present results demonstrated that there was no significant difference in CD133 and CD44 between SP cells and non-SP cells derived from the Tca8113 cell line. This different expression pattern of surface CSC markers may be due to the different cell lines of OSCC. Notably, the results of flow cytometry demonstrated that the ratio of ALDH1 ${ }^{+}$ in SP cells was increased $\sim 10$ times compared with non-SP 

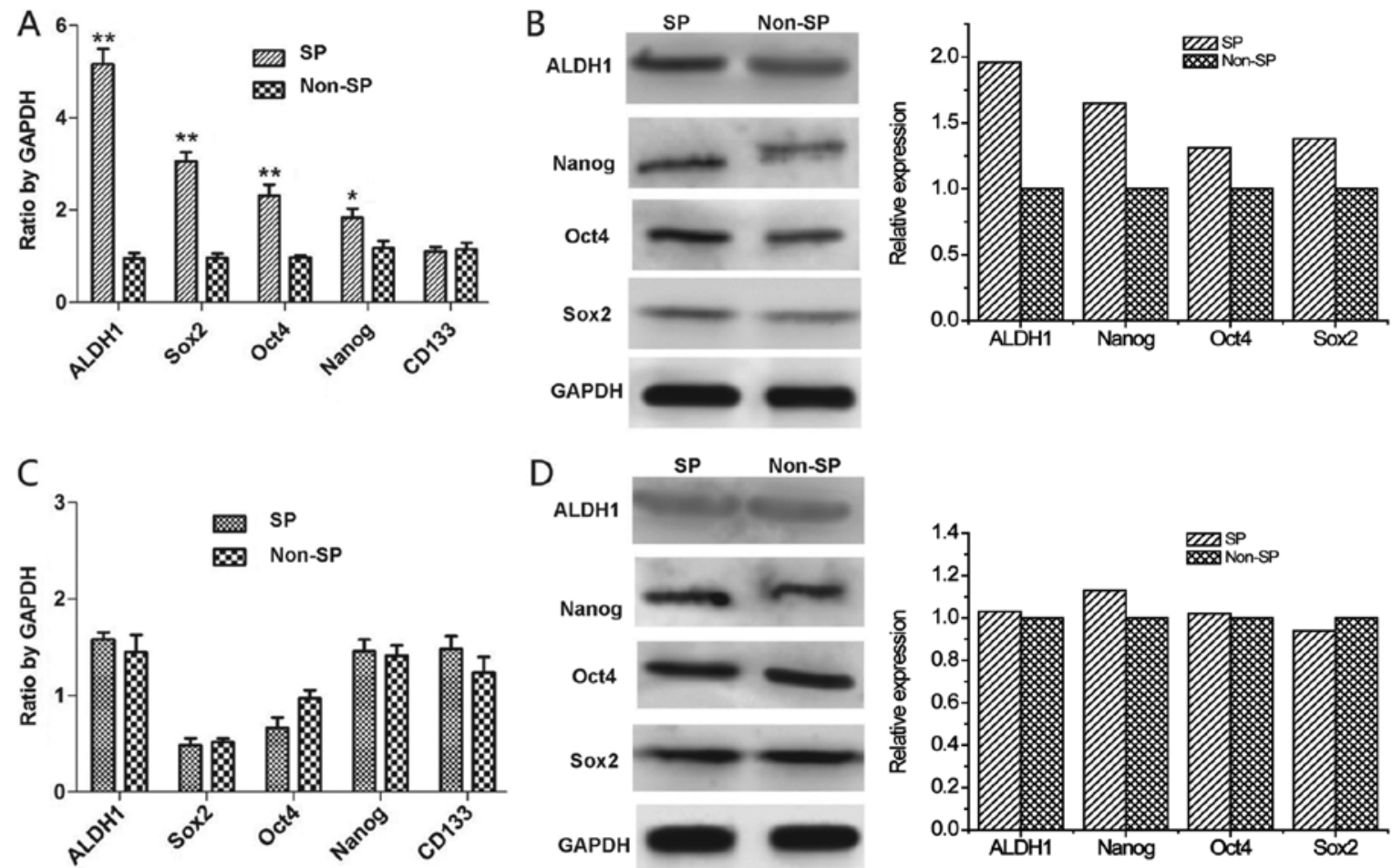

Figure 4. Expression of stem genes detected by RT-qPCR and western blotting. (A) Expressions of ALDH1, Sox2, Oct4, Nanog and CD133 mRNA by RT-qPCR in SP and non-SP cells. (B) Expressions of ALDH1, Sox2, Oct4 and Nanog protein by western blotting in SP and non-SP cells. (C) Expressions of ALDH1, Sox2, Oct4, Nanog and CD133 mRNA by RT-qPCR in SP and non-SP cells following differentiation by culturing in serum-supplemented medium for 14 days. (D) Expressions of ALDH1, Sox2, Oct4 and Nanog protein by western blotting in SP and non-SP cells following differentiation by culturing in serum-supplemented medium for 14 days. ${ }^{*} \mathrm{P}<0.05,{ }^{* *} \mathrm{P}<0.01$ vs. respective non-SP. RT-qPCR, reverse transcription-quantitative polymerase chain reaction; ALDH1, aldehyde dehydrogenase-1; Sox2, SRY-box 2; Oct4, POU class 5 homeobox 1; Nanog, nanog homeobox; CD133, CD133 antigen; SP, side population.

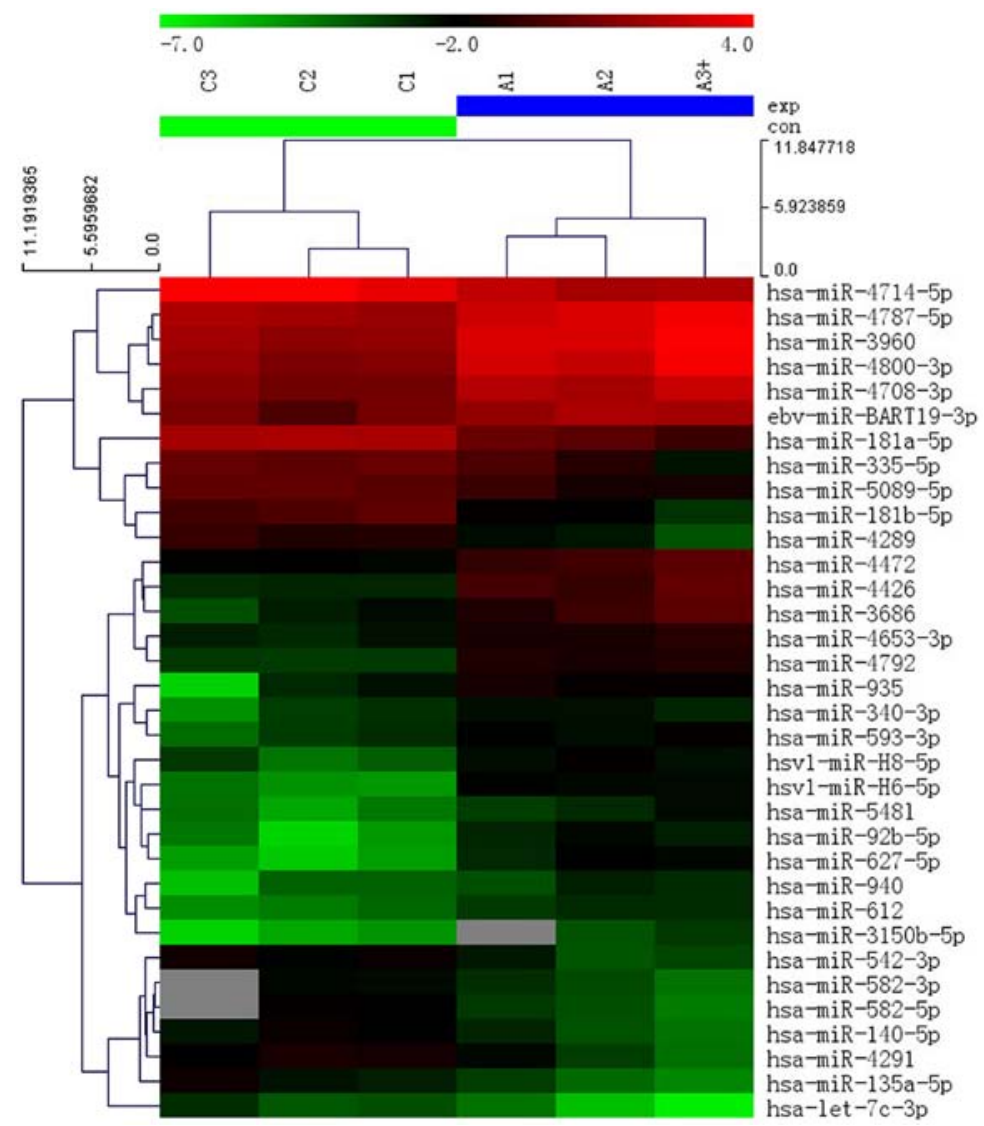

Figure 5. Hierarchical clustering analysis. Samples SP 1-3 represents SP cells numbering from 1-3; samples non-SP 1-3 represents the non-SP cells numbering from 1-3. Red represents relatively high expression levels of molecules; green represents with relatively low levels of expression. miR, microRNA. 

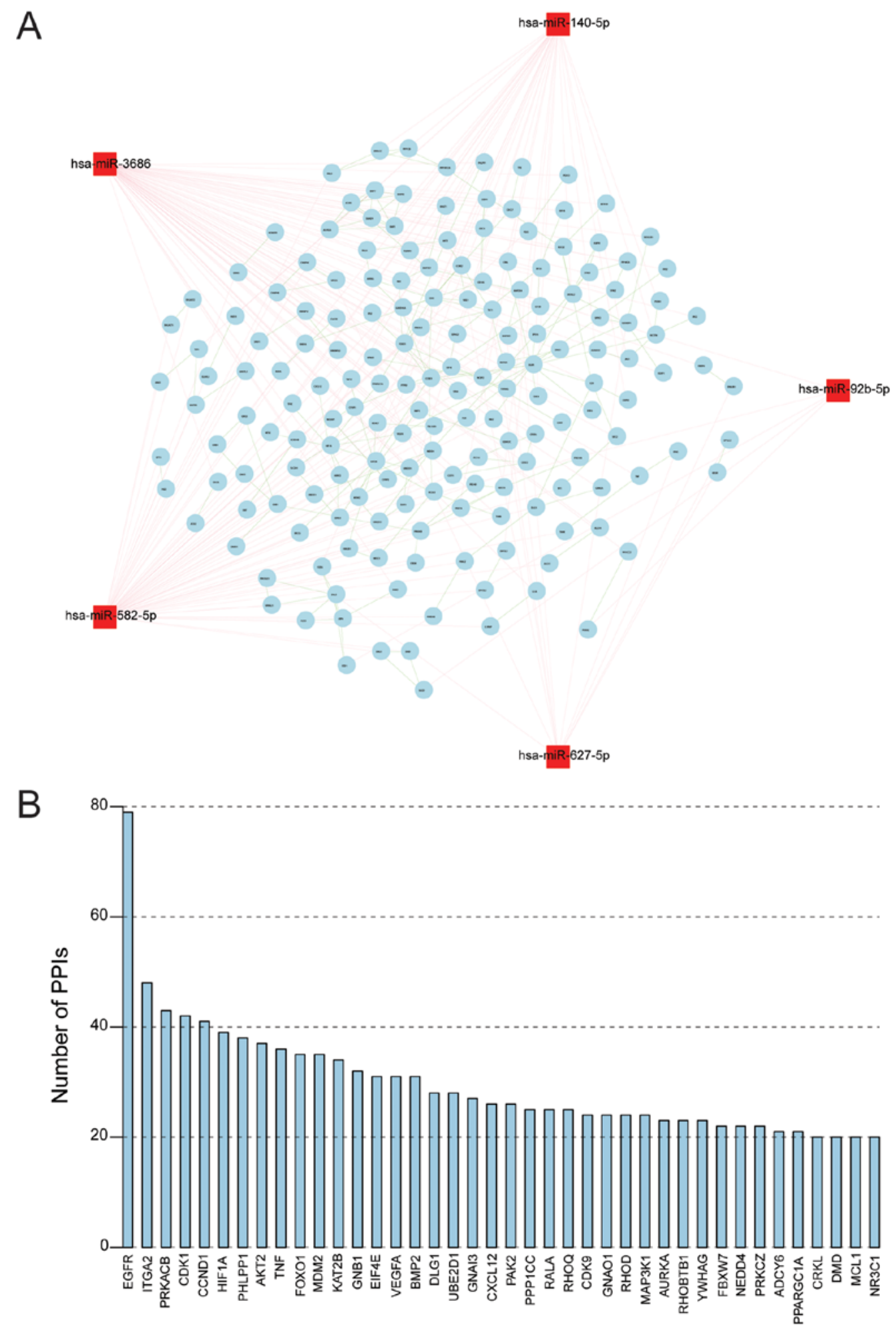

Figure 6. The miRNA-gene-gene regulatory network and important genes. (A) The miRNA-gene-gene regulatory network was constructed. (B) The PPI number of each gene in this network. miR, microRNA; PPI(s), protein-protein interaction(s).

cells. Additionally, overexpression of ALDH1 mRNA and protein in SP cells was detected by RT-qPCR and western blot analysis. To the best of our knowledge, this is the first study demonstrating the overexpression of ALDH1 in the stem-like OSCC SP cells. When the SP cells were incubated with SSM for 14 days, the percentage of ALDH1 was decreased between $7 \%$ and $>1 \%$, similar to the ordinary tumor cells. These results suggested that following culture in SSM for 14 days, the cancer stem-like SP cells were differentiated and, thus, no longer exhibited CSC properties. Furthermore, the Sox2, Oct4 and Nanog gene regulatory network have a role in the negative feedback loop in maintaining human embryonic stem cells $(42,43)$. The present study used cell proliferation, scratch and colony formation assays, flow cytometry, and RT-qPCR to detect mRNA and protein expression; the present results demonstrated that SP cells possess characteristics of CSCs. 
Microarray analysis of miRNAs identified 34 miRNAs associated with SP cells in Tca8113 cell lines. The microarray results suggested that 21 miRNAs exhibited high expression of tumor stem cells and 13 miRNAs exhibited low expression, and they may serve a role in the regulation of cell differentiation. There are specific miRNA expression profiles in CSCs, which provided relevant information for the establishment of a novel miRNA-based approach for diagnosis and treatment of OSCC (44). miRNAs are an abundant class of small non-coding RNAs, consisting of $\sim 22$ nucleotides that negatively regulate gene expression at the post-transcriptional level by blocking mRNA translation or degrading target mRNAs (45). The interaction between the genes in the network was statistically analyzed, and EGFR, ITGA2, PRKACB, CDK1 and CCND1 genes were in the top five genes in the miRNA regulatory network. EGFR is most notably regarded as a cancer-associated molecule. Overexpression of EGFR activated a number of principal pathways that were crucial for tumor growth, progression and survival (46). Elevated expression of EGFR has been demonstrated in oral cancer and is frequently associated with poor clinical outcome (47), thus representing a potential target for treatment. ITGA2 is one of the integrins involved in epithelial-mesenchymal transitions (EMT) (48). EMT is an important process associated with tumor metastasis (49). ITGA2 has been reported to have a role in multiple cancer types $(50,51)$. It has been reported that expression of ITGA11 in cancer-associated fibroblasts alters the tumor behavior of OSCC cells (52); however, the role of ITGA2 in OSCC has not been investigated previously, to the best of our knowledge. Targeting ITGA2 may improve the efficacy of treatment for patients with OSCC. Future studies may aim to investigate the 34 genes investigated.

There are a number of limitations of the present study. SP and non-SP cells were cultured in individual conditions (SFM and SSM), which may affect results. To describe the characteristics of SP and non-SP cells further, the cells require culturing in the same conditions following sorting and subjected to further analysis. Secondly, the results of the miRNA array have not been validated by PCR, which should be conducted in vitro and in vivo in further studies. Thirdly, although there was no significant difference in CD133 mRNA expression level between SP and non-SP cells, the expression of CD133 at the protein expression level requires investigation.

In conclusion, SP cells in Tca 8113 demonstrated increased capability of proliferation and colony formation compared with non-SP cells in vitro. Stem cell markers were overexpressed in SP cells compared with non-SP cells. In total, 21 miRNAs were upregulated and 13 miRNAs were downregulated in SP cells compared with non-SP.

\section{Acknowledgements}

The authors would like to thank Dr Yan Lv (Institute and Department of Stomatology, Chinese People's Liberation Army General Hospital, Beijing, China) for assistance.

\section{Funding}

The present study is supported by Beijing Municipal Natural Science Foundation of China (grant no. 7122174) and the
National Natural Science Foundation of China (grant no. 81271180).

\section{Availability of data and materials}

The datasets used and/or analyzed during the current study are available from the corresponding author on reasonable request.

\section{Authors' contributions}

WL and RSL designed the present study. WL, LLE, YB, XPK and HCL performed the experiments. HWL and HW performed the statistical analysis. WL and HCL wrote the manuscript. RSL, LLE and YB revised the manuscript. All authors approved the final version of the manuscript for publication.

\section{Ethics approval and consent to participate}

Not applicable.

\section{Patient consent for publication}

Not applicable.

\section{Competing interests}

The authors declare that they have no competing interests.

\section{References}

1. Argiris A, Karamouzis MV, Raben D and Ferris RL: Head and neck cancer. Lancet 371: 1695-1709, 2008.

2. Mascolo M, Siano M, Ilardi G, Russo D, Merolla F, De Rosa G and Staibano S: Epigenetic disregulation in oral cancer. Int J Mol Sci 13: 2331-2353, 2012

3. Clevers H: The cancer stem cell: Premises, promises and challenges. Nat Med 17: 313-319, 2011.

4. Reya T, Morrison SJ, Clarke MF and Weissman IL: Stem cells, cancer, and cancer stem cells. Nature 414: 105-111, 2001.

5. Chen K, Huang YH and Chen JL: Understanding and targeting cancer stem cells: Therapeutic implications and challenges. Acta Pharmacol Sin 34: 732-740, 2013.

6. Donnenberg VS and Donnenberg AD: Multiple drug resistance in cancer revisited: The cancer stem cell hypothesis. J Clin Pharmacol 45: 872-877, 2005.

7. Setoguchi T, Taga T and Kondo T: Cancer stem cells persist in many cancer cell lines. Cell Cycle 3: 414-415, 2004.

8. Hadnagy A, Gaboury L, Beaulieu R and Balicki D: SP analysis may be used to identify cancer stem cell populations. Exp Cell Res 312: 3701-3710, 2006.

9. Kondo T, Setoguchi T and Taga T: Persistence of a small subpopulation of cancer stem-like cells in the C6 glioma cell line. Proc Natl Acad Sci USA 101: 781-786, 2004.

10. Zhang P, Zhang Y, Mao L, Zhang Z and Chen W: Side population in oral squamous cell carcinoma possesses tumor stem cell phenotypes. Cancer Lett 277: 227-234, 2009.

11. Liu Y, Cui P, Chen J and Li W: Isolation and phenotypic characterization of side population cells in oral squamous cell carcinoma. Mol Med Rep 11: 3642-3646, 2015.

12. Yu CC, Hu FW, Yu CH and Chou MY: Targeting CD133 in the enhancement of chemosensitivity in oral squamous cell carcinoma-derived side population cancer stem cells. Head Neck 38 Suppl 1: E231-E238, 2016.

13. Chiou SH, Yu CC, Huang CY, Lin SC, Liu CJ, Tsai TH, Chou SH, Chien CS, Ku HH and Lo JF: Positive correlations of Oct-4 and Nanog in oral cancer stem-like cells and high-grade oral squamous cell carcinoma. Clin Cancer Res 14: 4085-4095, 2008. 
14. Hayashi S, Tanaka J, Okada S, Isobe T, Yamamoto G, Yasuhara R, Irie T, Akiyama C, Kohno Y, Tachikawa T and Mishima K: Lin28a is a putative factor in regulating cancer stem cell-like properties in side population cells of oral squamous cell carcinoma. Exp Cell Res 319: 1220-1228, 2013.

15. Bourguignon LY, Peyrollier K, Xia W and Gilad E: Hyaluronan-CD44 interaction activates stem cell marker Nanog, Stat-3-mediated MDR1 gene expression, and ankyrin-regulated multidrug efflux in breast and ovarian tumor cells. J Biol Chem 283: 17635-17651, 2008.

16. Zöller M: CD44: Can a cancer-initiating cell profit from an abundantly expressed molecule? Nat Rev Cancer 11: 254-267, 2011.

17. Zhang Q, Shi S, Yen Y, Brown J, Ta JQ and Le AD: A subpopulation of CD133(+) cancer stem-like cells characterized in human oral squamous cell carcinoma confer resistance to chemotherapy. Cancer Lett 289: 151-160, 2010.

18. Resetkova E, Reis-Filho JS, Jain RK, Mehta R, Thorat MA, Nakshatri $\mathrm{H}$ and Badve S: Prognostic impact of ALDH1 in breast cancer: A story of stem cells and tumor microenvironment. Breast Cancer Res Treat 123: 97-108, 2010.

19. Ota N, Ohno J, Seno K, Taniguchi K and Ozeki S: In vitro and in vivo expression of aldehyde dehydrogenase 1 in oral squamous cell carcinoma. Int J Oncol 44: 435-442, 2014.

20. Ginestier C, Hur MH, Charafe-Jauffret E, Monville F, Dutcher J, Brown M, Jacquemier J, Viens P, Kleer CG, Liu S, et al: ALDH1 is a marker of normal and malignant human mammary stem cells and a predictor of poor clinical outcome. Cell Stem Cell 1: 555-567, 2007.

21. Huang EH, Hynes MJ, Zhang T, Ginestier C, Dontu G, Appelman H, Fields JZ, Wicha MS and Boman BM: Aldehyde dehydrogenase 1 is a marker for normal and malignant human colonic stem cells (SC) and tracks SC overpopulation during colon tumorigenesis. Cancer Res 69: 3382-3389, 2009.

22. Silva IA, Bai S, McLean K, Yang K, Griffith K, Thomas D, Ginestier C, Johnston C, Kueck A, Reynolds RK, et al: Aldehyde dehydrogenase in combination with CD133 defines angiogenic ovarian cancer stem cells that portend poor patient survival. Cancer Res 71: 3991-4001, 2011.

23. Chen YC, Chen YW, Hsu HS, Tseng LM, Huang PI, Lu KH, Chen DT, Tai LK, Yung MC, Chang SC, et al: Aldehyde dehydrogenase 1 is a putative marker for cancer stem cells in head and neck squamous cancer. Biochem Biophys Res Commun 385: 307-313, 2009.

24. Ma S, Chan KW, Lee TK, Tang KH, Wo JY, Zheng BJ and Guan XY: Aldehyde dehydrogenase discriminates the CD133 liver cancer stem cell populations. Mol Cancer Res 6: 1146-1153, 2008.

25. Liu W, Wu L, Shen XM, Shi LJ, Zhang CP, Xu LQ and Zhou ZT: Expression patterns of cancer stem cell markers ALDH1 and CD133 correlate with a high risk of malignant transformation of oral leukoplakia. Int J Cancer 132: 868-874, 2013.

26. Wiklund ED, Gao S, Hulf T, Sibbritt T, Nair S, Costea DE, Villadsen SB, Bakholdt V, Bramsen JB, Sørensen JA, et al: MicroRNA alterations and associated aberrant DNA methylation patterns across multiple sample types in oral squamous cell carcinoma. PLoS One 6: e27840, 2011.

27. Scapoli L, Palmieri A, Lo Muzio L, Pezzetti F, Rubini C, Girardi A Farinella F, Mazzotta M and Carinci F: MicroRNA expression profiling of oral carcinoma identifies new markers of tumor progression. Int J Immunopathol Pharmacol 23: 1229-1234, 2010.

28. Zhang X, Su Y, Zhang M and Sun Z: Opposite effects of arsenic trioxide on the Nrf2 pathway in oral squamous cell carcinoma in vitro and in vivo. Cancer Lett 318: 93-98, 2012

29. Wang W, Li X, Wang F and Sun XY: Effect of TET1 regulating MGMT on chemotherapy resistance of oral squamous cell carcinoma stem cells. J Cell Biochem 119: 723-735, 2018.

30. Scharenberg CW, Harkey MA and Torok-Storb B: The ABCG2 transporter is an efficient Hoechst 33342 efflux pump and is preferentially expressed by immature human hematopoietic progenitors. Blood 99: 507-512, 2002

31. Pandey S, Walpole C, Cabot PJ, Shaw PN, Batra J and Hewavitharana AK: Selective anti-proliferative activities of Carica papaya leaf juice extracts against prostate cancer. Biomed Pharmacother 89: 515-523, 2017.

32. Livak KJ and Schmittgen TD: Analysis of relative gene expression data using real-time quantitative PCR and the 2(-Delta Delta C(T)) method. Methods 25: 402-408, 2001.
33. Wang X, Liu Q, Hou B, Zhang W, Yan M, Jia H, Li H, Yan D, Zheng F, Ding W, et al: Concomitant targeting of multiple key transcription factors effectively disrupts cancer stem cells enriched in side population of human pancreatic cancer cells. PLoS One 8: e73942, 2013.

34. Park T, Yi SG, Kang SH, Lee S, Lee YS and Simon R: Evaluation of normalization methods for microarray data. BMC Bioinformatics 4: 33, 2003.

35. Saeed AI, Sharov V, White J, Li J, Liang W, Bhagabati N, Braisted J, Klapa M, Currier T, Thiagarajan M, et al: TM4: A free, open-source system for microarray data management and analysis. Biotechniques 34: 374-378, 2003.

36. Eisen MB, Spellman PT, Brown PO and Botstein D: Cluster analysis and display of genome-wide expression patterns. Proc Natl Acad Sci USA 95: 14863-14868, 1998

37. Ho MM, Ng AV, Lam S and Hung JY: Side population in human lung cancer cell lines and tumors is enriched with stem-like cancer cells. Cancer Res 67: 4827-4833, 2007.

38. Tirino V, Desiderio V, Paino F, De Rosa A, Papaccio F, La Noce M, Laino L, De Francesco F and Papaccio G: Cancer stem cells in solid tumors: An overview and new approaches for their isolation and characterization. FASEB J 27: 13-24, 2013

39. Bonnet D and Dick JE: Human acute myeloid leukemia is organized as a hierarchy that originates from a primitive hematopoietic cell. Nat Med 3: 730-737, 1997.

40. Mackenzie IC: Growth of malignant oral epithelial stem cells after seeding into organotypical cultures of normal mucosa. J Oral Pathol Med 33: 71-78, 2004.

41. Locke M, Heywood M, Fawell S and Mackenzie IC: Retention of intrinsic stem cell hierarchies in carcinoma-derived cell lines. Cancer Res 65: 8944-8950, 2005.

42. Narayan S, Bryant G, Shah S, Berrozpe G and Ptashne M: OCT4 and SOX2 work as transcriptional activators in reprogramming human fibroblasts. Cell Rep 20: 1585-1596, 2017.

43. Marucci L: Nanog dynamics in mouse embryonic stem cells: Results from systems biology approaches. Stem Cells Int 2017: 7160419, 2017.

44. Polyak K and Weinberg RA: Transitions between epithelial and mesenchymal states: Acquisition of malignant and stem cell traits. Nat Rev Cancer 9: 265-273, 2009.

45. Shenouda SK and Alahari SK: MicroRNA function in cancer: Oncogene or a tumor suppressor? Cancer Metastasis Rev 28: 369-378, 2009

46. Lo HW and Hung MC: Nuclear EGFR signalling network in cancers: Linking EGFR pathway to cell cycle progression, nitric oxide pathway and patient survival. Br J Cancer 96 Suppl: R16-R20, 2007.

47. Ribeiro FA, Noguti J, Oshima CT and Ribeiro DA: Effective targeting of the epidermal growth factor receptor (EGFR) for treating oral cancer: A promising approach. Anticancer Res 34: 1547-1552, 2014

48. Liu X, Liang Z, Gao K, Li H, Zhao G, Wang S and Fang J: MicroRNA-128 inhibits EMT of human osteosarcoma cells by directly targeting integrin $\alpha 2$. Tumor Biol 6: 7951-7957, 2016.

49. Yang $\mathbf{J}$ and Weinberg RA: Epithelial-mesenchymal transition: At the crossroads of development and tumor metastasis. Dev Cell 14: 818-829, 2008.

50. Chin SP, Marthick JR, West AC, Short AK, Chuckowree J, Polanowski AM, Thomson RJ, Holloway AF and Dickinson JL: Regulation of the ITGA2 gene by epigenetic mechanisms in prostate cancer. Prostate 75: 723-734, 2015

51. Ding W, Fan XL, Xu X, Huang JZ, Xu SH, Geng Q, Li R, Chen D and Yan GR: Epigenetic silencing of ITGA 2 by MiR-373 promotes cell migration in breast cancer. PLoS One 10: e0135128, 2015.

52. Parajuli H, Sapkota D, Suleiman S, Cormack EM, Johannessen AC, Gullberg D and Costea DE: 28 Expression of integrin $\alpha-11$ by carcinoma associated fibroblasts modulates oral squamous cell carcinoma behavior. Oral Oncol 51: e36, 2015.

This work is licensed under a Creative Commons Attribution-NonCommercial-NoDerivatives 4.0 International (CC BY-NC-ND 4.0) License. 